\title{
THE CONTRIBUTION OF THE WORKERS OF KALMYKIA TO THE CONSTRUCTION OF THE RAILWAY ASTRAKHAN - KIZLYAR (OCTOBER 1941 - AUGUST 1942)
}

\author{
Vladimir B. Ubushaev \\ Kalmyk State University named after B.B. Gorodovikov, \\ Elista, Russian Federation
}

\begin{abstract}
The article reveals the contribution of the inhabitants of Kalmykia to the construction of the Astrakhan - Kizlyar railroad, which played an important role in the supply of Soviet troops during the Stalingrad battle. According to the author, this was truly a people's building. About 20 thousand people were sent from the Kalmyk ASSR to the construction site. The construction of the highway was carried out in very difficult circumstances: unfavorable natural and climatic conditions (the boundless uninhabited steppe, the constantly falling sandy and saline soil, summer heat, autumn heavy rains, strong winds, passing into storms, sweeping everything in its path, the same excavation work was often performed several times), almost complete absence of machinery and mechanisms, shortage of food and drinking water, systematic bombing by enemy aircraft. But even in these circumstances, builders, perfectly aware of the significance of their mission, managed to carry out assignments for $180-200 \%$, and for individual brigades - by $250 \%$. Thanks to the heroic labor of the builders, among them a considerable part were represented by women, old people and teenagers, a railway with a length of 356 kilometers was erected within the shortest possible time: for 10 months. Using the example of this construction, the author shows that the railways during the Great Patriotic War turned into a military factor of primary importance.

Key words: the Great Patriotic War, Kalmykia, railway, labour heroism, Stalingrad battle.

Citation. Ubushaev V.B. The Contribution of the Workers of Kalmykia to the Construction of the Railway Astrakhan - Kizlyar (October 1941 - August 1942). Vestnik Volgogradskogo gosudarstvennogo universiteta. Serija 4 , Istorija. Regionovedenie. Mezhdunarodnye otnoshenija [Science Journal of Volgograd State University. History. Area Studies. International Relations], 2017, vol. 22, no. 3, pp. 136-141. (in Russian). DOI: https://doi.org/ 10.15688/jvolsu4.2017.3.12.
\end{abstract}

\section{ВКЛАД ТРУЖЕНИКОВ КАЛМЫКИИ В СТРОИТЕЛЬСТВО ЖЕЛЕЗНОЙ ДОРОГИ АСТРАХАНЬ - КИЗЛЯР (ОКТЯБРЬ 1941 - АВГУСТ 1942 г.)}

\author{
Владимир Бадахаевич Убушаев \\ Калмыцкий государственный университет имени Б.Б. Городовикова, \\ г. Элиста, Российская Федерация \\ г. Элиста, Российская Федерация
}

Аннотация. В статье раскрывается вклад жителей Калмыкии в строительство железной дороги Астрахань - Кизляр, сыгравшей важную роль в снабжении советских войск в период Сталинградской битвы. По мнению автора, это была поистине народная стройка. Из Калмыцкой АССР на строительство было направлено около 20 тысяч человек. Сооружение магистрали велось в тяжелейших обстоятельствах, среди которых неблагоприятные природно-климатические условия (бескрайняя необжитая степь, постоянно осыпавшийся
} 
песчаный и солончаковый грунт, летний зной, осенние проливные дожди, сильные ветры, переходившие в бураны, сметавшие все на своем пути, из-за чего одни и те же земляные работы приходилось нередко выполнять по несколько раз), почти полное отсутствие машин и механизмов, нехватка продовольствия и питьевой воды, систематические бомбардировки вражеской авиации. Но даже в этих обстоятельствах строителям, прекрасно сознававшим значимость своей миссии, удавалось выполнять задания на 180-200 \%, а отдельным бригадам - на 250 \%. Благодаря героическому труду строителей, среди которых немалую часть составляли женщины, старики и подростки, железная дорога протяженностью 356 км была возведена в предельно сжатые сроки - за 10 месяцев. На примере этой стройки автор показывает, что железные дороги в годы Великой Отечественной войны превратились в военный фактор первостепенного значения.

Ключевые слова: Великая Отечественная война, Калмыкия, железная дорога, трудовой героизм, Сталинградская битва.

Цитирование. Убушаев В. Б. Вклад тружеников Калмыкии в строительство железной дороги Астрахань - Кизляр (октябрь 1941 - август 1942 г.) // Вестник Волгоградского государственного университета. Серия 4, История. Регионоведение. Международные отношения. - 2017. - Т. 22, № 3. - C. 136-141. - DOI: https://doi.org/10.15688/jvolsu4.2017.3.12.

Советские железнодорожники проделали в годы войны огромную работу. На тысячи километров с запада на восток они перевозили тонны оборудования, материалов, зерна и миллионы спасавшихся от германских фашистов советских людей.

К лету 1942 г. советскому командованию стало ясно, что враг рвется к Волге в район Сталинграда, стремясь захватить этот важный стратегический объект и один из крупнейших промышленных районов страны. Согласно директиве германского верховного главнокомандования № 41 от 5 апреля 1942 г. под названием «Блау», перед гитлеровскими войсками была также поставлена в качестве одной из главных задач «в любом случае попытаться достигнуть Сталинграда или, по крайней мере, подвергнуть его воздействию... тяжелого оружия с тем, чтобы он потерял свое значение как центр военной промышленности и узел коммуникаций» (цит. по: [8, с. 80]).

В ночь на 12 июля 1942 г. фашистские войска вторглись в пределы Сталинградской области. 14 июля 1942 г. указом Президиума Верховного Совета СССР область была объявлена на военном положении. Сражение в районе нижней Волги приобретало все более ожесточенный характер. В середине июля 1942 г. превосходящим силам противника удалось в значительной мере блокировать Сталинград.

Еще в первой половине июля 1942 г. выбыла из строя железная дорога СталинградЛихая, а 30 июля 1942 г. гитлеровцы заняли станцию Ремонтная на железнодорожном направлении Сталинград - Тихорецкая, перере- зав тем самым транспортную связь волжского города с югом страны [3, с. 169].

Задача снабжения войск боеприпасами, техникой, снаряжением, продовольствием и людским пополнением осложнялось тем, что части Красной Армии, оборонявшие районы Нижней Волги и Северный Кавказ, базировались на сравнительно бедной сети железных дорог. Если в приграничной полосе густота железнодорожной сети доходила до 70 км на 1000 кв. км, то в районе между Днепром и Доном она снизилась до 45 км, а в полосе между Доном и Волгой, на Кубани и Северном Кавказе - даже до 14 км.

Главная тяжесть по обеспечению перевозок для защитников Сталинграда легла на плечи железнодорожников, и в первую очередь на коллективы Рязано-Уральской и Юго-Восточной железных дорог, которые одновременно питали несколько фронтов: Сталинградский, Юго-Восточный, Юго-Западный и частично Воронежский. При этом важнейшими железнодорожными коммуникациями, по которым осуществлялся основной подвоз в район Сталинграда, являлись однопутные линии: Поворино - Сталинград протяженностью 344 км (пропускная способность - до 21 пары поездов в сутки) и Урбах - Баскунчак - Ахтуба протяженностью 289 км (пропускная способность в груженом направлении до 19 и обратно - 11 поездов в сутки) [7, с. 21].

В результате наступления гитлеровских войск к осени 1941 г. выбыла из строя главная железнодорожная магистраль страны на южном направлении Москва - Курск - Харьков Ростов - Баку, затем почти полностью - Юго- 
Восточная железная дорога. В тяжелых условиях, сложившихся в районе Сталинграда, необходима была железнодорожная ветка, которая соединила бы Северный Кавказ и Закавказье с Волгой и центром страны.

Еще 16 августа 1941 г. было принято постановление Совнаркома СССР и ЦК ВКП(б) «О военно-хозяйственном плане на IV квартал 1941 г. и на 1942 г. по районам Поволжья, Урала, Западной Сибири, Казахстана и Средней Азии», в котором в одном из пунктов в порядке поручения Наркомату путей сообщения СССР было записано: «...в целях усиления пропускной способности железных дорог в районах Поволжья... приступить в IV квартале 1941 г. к строительству железной дороги Кизляр - Астрахань, обеспечив открытие рабочего движения по этой дороге к 1 августа 1942 г.» [5, с. 48].

Железную дорогу должны были строить трудящиеся Астраханского округа, Калмыцкой АССР, восточных районов Орджоникидзевского края. Трасса должна была пройти по Черным землям, Кизлярским пастбищам, безводным степям Калмыкии. Переход через Волгу намечался у поселка Трусово и далее железнодорожная линия должна была примкнуть к станции Астрахань-П [4].

Первые отряды строителей Калмыкии стали прибывать на место будущей железной дороги в начале октября 1941 года. Кругом лежала бескрайняя, необжитая степь. Были трудности с доставкой питьевой воды; ее подвозили на подводах с притоков Волги, из различных речушек или близлежащих колодцев.

Прежде всего на помощь строителям дороги пришли местные партийные и советские органы, которые провели значительную работу по мобилизации населения на строительство железной дороги Астрахань - Кизляр.

Условия работы были очень тяжелыми. Не хватало продуктов питания. Постоянно шли проливные дожди. Землю долбили ломом. Но ни дожди, ни грязь по колено, ни степные бураны не могли стать препятствием в достижении поставленной цели. «Труд на спецстройке стал делом чести каждого», - вспоминала бывший строитель, бригадир бригады по сооружению земляного полотна Александра Ивановна Ларина, которая находится на заслуженном отдыхе и проживает в поселке Лиман Астраханской области.

Действительно, условия труда были неимоверно тяжелыми. Песчаный и солончаковый грунт быстро осыпался. Этому способствовали также сильные ветры, нередко переходившие в бураны и сметавшие все на пути. Земляные работы приходилось переделывать по несколько раз. «Песчаная пыль, тучами поднимавшаяся ветрами, слепила глаза, попадая в обувь и одежду, затрудняла движение. А в степи не хватало воды. Невыносимо палило солнце. Зной усиливал жажду, вспоминал один из строителей участка железнодорожного полотна Басы - Зензели Улюмджи Лиджиев, - но, несмотря на это, работы не прекращались ни на минуту».

Вся будущая трасса железной дороги Астрахань - Кизляр была разбита на участки по числу улусов, на каждом из них создали строительные бригады; назначали бригадиров из числа коммунистов и комсомольцев. Многие строительные бригады выполняли задания на 180-200\%, а бригада землекопов А. Надбитова держала переходящее Красное знамя и выполняла нормы на 250 \%. С каждым днем темп строительных работ нарастал. К концу ноября 1941 г. были произведены все земляные работы.

Дорогу строили в основном женщины, старики и подростки. В целях быстрого окончания строительства некоторые улускомы партии решили пойти даже на такой шаг, как направление старшеклассников на строительство железной дороги с временным отрывом их от занятий. Вместе с ними направляли и учителей. За всеми выезжающими работниками школ сохранялся заработок в размере основной ставки, а оставшиеся учителя получали зарплату согласно недельной нагрузке за проведенные занятия.

Уже 1 декабря 1941 г. объем выполненной работы достиг 94 тыс. куб. м и было подготовлено 210 км земляного полотна. К 1 января 1942 г. на участке трассы, проходившей по территории Калмыцкой АССР, работало 9500 человек, 3030 подвод. К этому времени было выполнено 2 млн 800 тыс. куб. м земляных работ, возведено земляное полотно протяженностью 280 км. Началась укладка шпал и рельсов [2, с. 38]. В январе 1942 г. по 
всей трассе Астрахань - Кизляр под укладку рельсов было подготовлено 311 км земляного полотна.

В конце января 1942 г. по приказу Наркомата путей сообщения СССР весь коллектив бывшего Украинского треста должен был срочно отправиться на новую трассу: Вольск-Сызрань. Северная часть стройки (у станции Астрахань-II) оказалась, таким образом, полностью оголенной. Лишь к концу февраля 1942 г. появились новые строительные участки.

В феврале 1942 г. через Волгу по льду строители проложили временный путь и перебросили на правый берег паровоз и 20 двухосных платформ. Впоследствии уже на баржах перевезли еще 3 локомотива и 100 платформ [1]. В результате огромного труда к концу мая 1942 г. были завершены земляные работы в пойме, и вслед за этим были произведены укрепительные работы.

Большое внимание уделялось улусными партийными и советскими органами вопросам снабжения строителей продовольственными и промышленными товарами. Нередко бывало и так, что некоторые колхозы не подвозили вовремя продукты питания рабочим, направленным ими же на строительство. Учитывая такие вопиющие факты, исполком Лаганского улусного Совета принял постановление «О снабжении продуктами питания рабочих и служащих предприятий и учреждений, работающих на строительстве железной дороги Астрахань - Кизляр».

Технически наиболее сложным объектом оказалась паромная переправа через Волгу. Рельсы укладывали поперек больших спаренных баржей, и на каждом таком пароме умещалось до 50 вагонов. В начале было построено 2 пары причалов и 4 парома. Но они не справлялись с потоком грузов. Пришлось соорудить еще 2 пары причалов и 7 паромов. За август 1942 г. переправа была полностью освоена, и переброска подвижного состава достигла 450-500 вагонов в сутки. На сооружении переправы особо отличились мотострелки, которыми руководили специалисты-железнодорожники Баренбой и Цурюпа. Впоследствии они были удостоены высоких правительственных наград [6, с. 39].

Особенно тяжелыми были для строителей июль и август 1942 года. Фронт проходил уже параллельно строящейся железнодорожной линии на расстоянии нескольких десятков километров. Систематически, почти каждый день, с воздуха линию бомбили фашистские самолеты, но бомбежки противника не давали большого эффекта, так как крупных сооружений на трассе, кроме самого железнодорожного полотна в то время еще не было. Строительство станционных сооружений планировалось во вторую очередь.

В результате упорного напряженного труда коллектива строителей и местного населения строительство железной дороги Астрахань-Кизляр было завершено 4 августа 1942 года. Это случилось в 17 часов жаркого дня. Шедшие навстречу друг к другу строительные батальоны состыковали путь. Как только забили последний костыль, строители расступились перед составами, следовавшими по пятам кизлярских путейцев, и по всей трассе было открыто сквозное движение.

Руководство стройки в лице Э. Левина и В. Савинова направило 7 августа 1942 г. в Сталинградский обком ВКП(б) А.С. Чуянову, Астраханский окружком ВКП(б) В.А. Голышеву, Калмыцкий обком ВКП(б) П.В. Лаврентьеву, Орджоникидзевский крайком ВКП(б) М.А. Суслову, Кизлярский окружком ВКП(б) П.М. Ермаковой рапорт коллектива строителей железной дороги Кизляр - Астрахань о завершении укладки главного пути.

Текущие строительные работы на трассе продолжались до конца декабря 1942 года. Об этом свидетельствует переписка Управления строительства Наркомата путей сообщения СССР с Калмыцким Обкомом партии и Совнаркомом Калмыцкой АССР.

Таким образом, трудящиеся Калмыцкой ACCP, Астраханской области и восточных районов Ставропольского (Орджоникидзевского края) проявили трудовой подвиг, выполнив важное правительственное задание строительство железной дороги Астрахань Кизляр за 10 месяцев. Это стоило больших усилий строителям железнодорожной магистрали, но они знали, что это есть их трудовой вклад в разгром фашистской Германии. Поистине боевой подвиг совершили воины 110-й Калмыцкой Кавдивизии и другие воинские подразделения, защищая железную дорогу от нападения фашистских войск. 
С августа по октябрь 1942 г. по новой железнодорожной линии Астрахань - Кизляр в район Сталинграда проследовало 16 тысяч четырехосных цистерн (около одного миллиона тонн) горючего для боевой техники, 1500 паровозов, множество вагонов с различными грузами [6, с. 51].

Таким образом, через безводные степи Калмыкии, по Черным землям, Кизлярским пастбищам, полупустынную Калмыцкую степь вручную самоотверженным трудом местного населения была проложена железнодорожная магистраль Астрахань - Кизляр протяженностью 356 км.

Это была подлинно народная стройка. Огромную помощь строителям оказало местное население. Только одна Калмыцкая АССР мобилизовала на строительство около 20 тысяч человек, из них более 700 награждены за свой труд Почетными грамотами Президиума Верховного Совета республики.

От четкой работы железных дорог во многом зависели крупнейшие операции советских войск, включая величайшую по своему значению Сталинградскую битву. Железные дороги в годы Великой Отечественной войны превратились в военный фактор первостепенного значения.

\section{СПИСОК ЛИТЕРАТУРЫ}

1. Гудок. - 1967. -28 нояб.

2. Кичиков, М. Л. Во имя победы над фашизмом: очерки истории Калмыцкой АССР в годы Великой Отечественной войны / М. Л. Кичиков. - Элиста : Калмиздат, 1970. -208 с.

3. Куманев, Г. А. На службе фронта и тыла: железнодорожный транспорт СССР накануне и в годы Великой Отечественной войны, 1938-1945 / Г. А. Куманев. - М. : Наука, 1976. -455 с.

4. Левин, Э. И. Линия мужества / Э. И. Левин // Волга. - 1975. - 9 мая.

5. Решения партии и правительства по хозяйственным вопросам : сб. док. за 50 лет : в 5 т. Т. 3.М. : Политиздат, 1986. - 751 с.

6. Убушаев, В. Б. Дорога великой победы / В. Б. Убушаев. - Элиста : Изд-во Калмыц. ун-та, 2012. $-123 \mathrm{c}$.
7. Харламова, Ю. А. Магистраль нефти / Ю. А. Харламова // Вопросы отечественной и зарубежной истории глазами начинающих исследователей : сб. студ. и асп. ст. - Ставрополь : Изд-во Ставропол. гос. ун-та, 2002. - С. 19-25.

8. Януш, С. В. Войсковые операции Советской армии в битве за Кавказ (1942-1943 гг.) / С. В. Януш. - Ставрополь : Ставропол. книж. изд-во, 2005. -575 с.

\section{REFERENCES}

1. Gudok, 1967, November 28.

2. Kichikov M.L. Vo imya pobedy nad fashizmom: ocherki istorii Kalmytskoy ASSR v gody Velikoy Otechestvennoy voyny [In the Name of Victory over Fascism: Essays on the History of the Kalmyk ASSR during the Great Patriotic War]. Elista, Kalmizdat Publ., 1970. $208 \mathrm{p}$.

3. Kumanev G.A. Na sluzhbe fronta i tyla: zheleznodorozhnyy transport SSSR nakanune iv gody Velikoy Otechestvennoy voyny, 1938-1945 [At the Service of the front and Rear: Railway Transport of the USSR on the Eve and during the Great Patriotic War, 1938-1945]. Moscow, Nauka Publ., 1976. 455 p.

4. Levin E.I. Liniya muzhestva [Line of Courage]. Volga, 1975, May 9.

5. Resheniya partii $i$ pravitelstva po khozyaystvennym voprosam: sbornik dokumentov za 50 let. V 5 t. T. 3 [Decisions of the Party and Government on Economic Issues: Collection of Documents for 50 Years. In 5 vols. Vol. 3]. Moscow, Politizdat Publ., 1986. 751 p.

6. Ubushaev V.B. Doroga velikoy pobedy [The Road of Great Victory]. Elista, Izd-vo Kalmytskogo unta, 2012. $123 \mathrm{p}$.

7. Kharlamova Yu.A. Magistral nefti [Main Oil Pipeline]. Voprosy otechestvennoy i zarubezhnoy istorii glazami nachinayushchikh issledovateley: sbornik studencheskikh $i$ aspirantskikh statey [Questions of Domestic and Foreign History as Viewd by Beginning Researchers: Collection of Students' and Postgraduates' Articles]. Stavropol, Izd-vo Stavropol. gos. un-ta, 2002, pp. 19-25.

8. Yanush S.V. Voyskovyye operatsii Sovetskoy armii v bitve za Kavkaz (1942-1943 gg.) [Military Operations of the Soviet Army in the Battle for the Caucasus (1942-1943)]. Stavropol, Stavropol. knizh. izd-vo, 2005.575 p. 
В.Б. Убушаев. Вклад тружеников Калмыкии в строительство железной дороги Астрахань - Кизляр

\section{Information About the Author}

Vladimir B. Ubushaev, Honored Academician of the Russian Federation, Doctor of Sciences (History), Professor, Department of History of Russia, Kalmyk State University named after B.B. Gorodovikov, Pushkina St., 11, 358000 Elista, Russian Federation, ubushaev_vb@mail.ru, http:// orcid.org/0000-0002-7939-1774

\section{Информация об авторе}

Владимир Бадахаевич Убушаев, заслуженный деятель науки РФ, доктор исторических наук, профессор кафедры истории России, Калмыцкий государственный университет имени Б.Б. Городовикова, ул. Пушкина, 11, 358000 г. Элиста, Российская Федерация, ubushaev_vb@mail.ru, http://orcid.org/0000-0002-7939-1774 